\title{
NPD project portfolio selection using reinvestment strategy in competitive environment
}

\author{
Alireza Ghassemi and Mohsen Sadegh Amalnick*
}

School of Industrial and Systems Engineering, College of Engineering, University of Tehran, Iran

\begin{tabular}{l}
\hline C H R O N I C L E \\
\hline Article history: \\
Received January 152017 \\
Received in Revised Format \\
April 12017 \\
Accepted May 42017 \\
Available online \\
May 52017 \\
\hline Keywords: \\
New product development \\
Project portfolio selection \\
Reinvestment strategy \\
Competitive environment \\
Zero-One-Integer-Programming
\end{tabular}
A B S T R A C T

\begin{abstract}
This study aims to design a new model for selecting most fitting new product development projects in a pool of projects. To catch the best model, we assume new products will be introduced to the competitive markets. Also, we suppose the revenue yielded by completed projects can be reinvested on implementation of other projects. Other sources of financing are borrowing loans from banks and initial capital of the firm. These limited resources determine most evaluated projects to be performed. Several types of interactions among different projects are considered to make the chosen projects more like a portfolio. In addition, some numerical examples from the real world are provided to demonstrate the applicability of the proposed model. These examples show how the particular considerations in the suggested model affect the results.
\end{abstract}

\section{Introduction}

New product development (NPD) consists of the activities of the firm that lead to a stream of new or changed product market offerings over time. This includes the generation of opportunities, their selection and transformation into manufactured products and activities offered to customers, and the institutionalization of improvements in the NPD activities themselves (Loch \& Kavadias, 2008). This definition emphasizes on commercialization of the output and declares the difference between NPD and academic research. Also, any NPD project is susceptible to uncertainty regarding the success of its development. This uncertainty relates to the commercial success of the resulting product, which is influenced by market conditions (Kettunen et al., 2015). There is a high risk of R\&D based innovation being commercialized, especially in the innovation transfer process which is a concern to many entrepreneurs and researchers (Karaveg et al., 2015). To have the customers satisfied, improving the quality of the product must be kept up (Rajabi Asadabadi, 2014). A key issue in NPD and innovation has been managing uncertainty based on evolving technologies (Krishnan \& Ulrich, 2001). While delaying the introduction of new products allows development teams to incorporate improved technologies, it might also result in a significant loss of market opportunities (Clark, 1989). The product launching decisions in combination with launching decisions of competitors could form the competitive dynamics

* Corresponding author Tel: +98 (21) 66409517

E-mail: amalnick@ut.ac.ir (M. S. Amalnick)

(C) 2018 Growing Science Ltd. All rights reserved. doi: $10.5267 /$ j. ijiec.2017.5.001 
over time (Bhaskaran \& Ramachandran, 2011). Further, companies present NPD projects with the purpose of building the foundation for businesses that generate future revenues (Vilkkumaa et al., 2014). This attitude reflects the importance of decision making by strategic tools. Hence, we considered an NPD project beside other NPD projects to make a portfolio. Shenhar et al. (2001) believe projects and especially project portfolios are powerful strategic weapons. A project portfolio is defined as a set of projects that are executed and managed under the management and sponsorship of a particular organizations (Archer \& Ghasemzadeh, 1999). Choosing the "right projects" is an important part of strategic management in organizations. Even though making choices among alternative courses of action is a frequent activity in every organizations (Salo et al., 2011). A common and critical issue in any organization is about how to allocate resources to candidate projects while there are some interdependencies among them (Beheshti Pour et al., 2013). This area of research has been under tremendous investigation using either quantitative or qualitative analysis (Ahari et al., 2011).

Generally, NPD project portfolio selection is about choosing some projects among a set of available projects, within a certain time horizon regarding budget limitation. After commencing the project, expenditure relating to performing the project begins until the project ends and the final product launches into the market. Obviously, delaying in launching the product could reduce the return of the final product in the competitive market. The money that is gained after introducing new product may be reinvested in another project. The objective of this problem is to create the best set of projects as a portfolio and a schedule of their implementations.

The rest of the paper is organized as follows. Section 2 describes background literature and explores the gap between previous studies. Section 3 introduces a new model which fulfills the gap in the previous section. Section 4 discusses about a case study and some numerical analysis will be applied in order to determine sensitive parameters. And finally the conclusion of the paper is given in the last section.

\section{Background}

Despite the number of literature about NPD portfolio selection is few, there is an extensive literature on portfolio theory that focuses on the project selection problem (Iamratanakul et al., 2008). The general models are qualitative frameworks applied to select projects through several complex conceptual frameworks (Archer \& Ghasemzadeh, 1999; Bitman \& Sharif, 2008; Ghasemzadeh \& Archer, 2000; Meskendahl, 2010; Boone, 2001).

In other researches, quantitative and mathematical models are introduced to solve the problem. Various approaches are utilized to assemble projects in a portfolio. Some studies considered projects as zero-one variables (Hassanzadeh et al., 2014; Pendharkar, 2014; Shakhsi-Niaei et al., 2011) that choosing or not choosing the projects is the goal. Some solve the problem in a way of prioritization of projects (Dutra et al., 2014; García-Melón et al., 2015; Mohanty et al., 2005). This attitude determines the priority of projects to be implemented. Moreover, based on this priority, limited resource would be allocated. Practitioners are able to schedule activities of projects alongside the portfolio selection (Carazo et al., 2010; Coffin \& Taylor III, 1996). If managers make decisions in tactical level, they can allocate resources to projects instead of selecting the projects (Jelassi, 1999; Mehrez \& Sinuany-Stern, 1983; Solak et al., 2010). Another approach is distinguishing between dominated and non-dominated solutions of the problem (Liesiö \& Salo, 2012). In our model, a specific product will be launched in the future. Thus, the amount of resource which is required for implementing the projects are determined and resource allocation approaches are not useful.

For modelling the problem, a wide spectrum of mathematical programming methods is used. Most of recent are in the category of ILP (Liesiö et al., 2007; Mavrotas \& Pechak, 2013). With regard to continuous variables that are created during the definition of the problem, MILP is applicable (Carlsson et al., 2007; Pendharkar, 2014). Non-linear functions of variables make more complicated models 
(Abbassi et al., 2014) and academicians practice NLIP if there are discrete functions, too. Other subfields of mathematical optimizations like LP (Wei \& Chang, 2011) have been implemented in recent years. In this paper, there is not any continuous variables and all of them are binary and integer variable. Therefore, ZOIP will be performed for modelling problem.

Researchers have accomplished multiple methods in order to deal with uncertainty in data. Each method considers the problem in its particular attitude. (Dutra et al., 2014; Medaglia et al., 2007) used Monte Carlo simulation. Fuzzy theory is another way to handle uncertainty (Ghapanchi et al. 2012; KhaliliDamghani et al., 2013). Robust programming (Liesiö et al., 2008) and interactive programming (Hassanzadeh et al., 2014) may reduce the effect of uncertainty. Techniques based on multiple scenarios are helpful, too (Gemici-Ozkan et al., 2010; Solak et al., 2010). In this paper, uncertainty originates from competitive environment. In order to confront with this type of uncertainty, most of the studies considered dynamic nature of the model and applied flexibility management (Bardhan et al., 2004; Brandão \& Dyer, 2011; Wang \& Hwang, 2007). This approach holds unnecessary details about the problem and makes it more complex. In other studies, game theory is a major helpful tool (Canbolat et al., 2012; Etro, 2007; Imai \& Watanabe, 2006). Due to the changeable conditions of the environment and for avoiding the complexity of the problem, we applied the expected value concept to actualize the competitive environment.

\section{Table 1}

Literature Review

\begin{tabular}{|c|c|c|}
\hline Authors & in focus of analysis & Key Tools \\
\hline $\begin{array}{l}\text { (Gerchak \& Parlar, } \\
\text { 1999) }\end{array}$ & $\begin{array}{l}\text { The competitive situation between two firms for resource allocation on } \\
\text { limited R\&D projects }\end{array}$ & Game theory \\
\hline (Souza, 2004) & $\begin{array}{l}\text { The competition between two firms for introducing new products to } \\
\text { market }\end{array}$ & Game theory \\
\hline $\begin{array}{l}\text { (Chao \& Kavadias, } \\
\text { 2008) }\end{array}$ & $\begin{array}{l}\text { Balance between incremental and radical innovations for developing } \\
\text { right new products in portfolio }\end{array}$ & Strategic Bucket \\
\hline $\begin{array}{l}\text { (Golany \& Rothblum, } \\
\text { 2008) }\end{array}$ & $\begin{array}{l}\text { Investments in development projects within competitive environments } \\
\text { under uncertainty }\end{array}$ & Linear Programming \\
\hline (Solak et al., 2010) & $\begin{array}{l}\text { Dynamic selection of R\&D projects and determination of resource } \\
\text { allocation in a portfolio }\end{array}$ & Stochastic Programming \\
\hline $\begin{array}{l}\text { (Gemici-Ozkan et al., } \\
\text { 2010) }\end{array}$ & Multi-phase decision support system for R\&D portfolio selection & $\begin{array}{l}\text { Comprehensive } \\
\text { Framework }\end{array}$ \\
\hline $\begin{array}{l}\text { (Shakhsi-Niaei et al., } \\
\text { 2011) }\end{array}$ & $\begin{array}{l}\text { Multi criteria decision making and Monte Carlo simulation for R\&D } \\
\text { project selection }\end{array}$ & $\begin{array}{l}\text { Comprehensive } \\
\text { Framework }\end{array}$ \\
\hline (Wei \& Chang, 2011) & $\begin{array}{l}\text { Uncertainty and impact of several criteria on decision making for } \\
\text { selecting new products }\end{array}$ & $\begin{array}{l}\text { Fuzzy Linear } \\
\text { Programming }\end{array}$ \\
\hline (Canbolat et al., 2012) & $\begin{array}{l}\text { A race among multiple firms that compete over the development of a } \\
\text { product }\end{array}$ & Game theory \\
\hline (Belenky, 2012) & Reinvesting during time horizon in project portfolio selection & Boolean Programming \\
\hline (Wang \& Yang, 2012) & Managerial flexibility in an innovative R\&D project & Real Options \\
\hline (Lin \& Zhou, 2013) & The Cross-market effect on R\&D project portfolio & Game theory \\
\hline $\begin{array}{l}\text { (Hassanzadeh et al., } \\
\text { 2014) }\end{array}$ & Imprecise information in objective of $\mathrm{R} \& \mathrm{D}$ project selection & Robust Optimization \\
\hline (Jafarzadeh et al., 2015) & Flexible time horizon considering reinvestment in project selection & Integer Programming \\
\hline (Kettunen et al., 2015) & $\begin{array}{l}\text { Managerial flexibility for developing new product in competitive } \\
\text { environment }\end{array}$ & Dynamic Programming \\
\hline (Wang \& Song, 2016) & Time-dependent budget on reinvestment strategy & Integer Programming \\
\hline
\end{tabular}

In Table 1, most comprehensive literatures are introduced and their main focuses are expressed. Based on these papers, there is a sensible gap: Academicians had not paid attention to the competitive environment of NPD projects in integration with reinvestment strategy in portfolio selection. 


\section{Formulation}

In this model, there are $m$ available NPD projects with different durations. The final products of projects are launched to the market and particular return would be achieved, which is reducing moment to moment ${ }^{1}$. In addition, the interactions among different projects affect the implementation of the portfolio. Interactions are categorized into four types which will be defined in the following. Moreover, for investing in projects, the firm is able to use a variety of loans and an initial investment. Note that all of the decision makings in this model will be executed in a finite time horizon.

First, we conduct some equations for a single project in competitive environment.

\subsection{Competitive environment}

According to Kettunen et al. (2015) two market characteristics namely (i) competitive intensity of the market environment, and (ii) the market's degree of innovation demonstrates market's condition. To understand these concepts and adopt them in our model, let;

$I=\{1, \ldots, m\}$ be the set of available projects,

$T H=\{0,1, \ldots, T, \ldots\}$ be the set of infinite time instants, generally, not necessarily equal segments,

$\tau_{i j}$ be the competitive intensity of the market environment for product $i \in I$ at moment $j \in T H$,

$p_{i j}$ be the market's degree of innovation for product $i \in I$ at moment $j \in T H$,

$q_{i j}$ be the weakness of competitive market for product $i \in I$ at moment $j \in T H$,

$\phi_{i j}$ be the firm performance for product $i \in I$ at moment $j \in T H$,

$\gamma_{i j}$ be the non-negative random variable of the market performance for product $i \in I$ at moment $j \in T H$ and given $\gamma_{i 0}$ is the initial market performance for product $i \in I$

$d_{i j}$ be the random variable of product $i \in I$ return at moment $j \in T H$,

As we step forward in time, the market performance changes as a function of two parameters. The following equation represents how these parameters work;

$$
\gamma_{i j}=\left\{\begin{array}{l}
\gamma_{i(j-1)}+\tau_{i(j-1)} \text { with probability } p_{i j} \\
\gamma_{i(j-1)} \quad \text { with probability }\left(1-p_{i j}\right)
\end{array} \text { for } j \in T H-\{0\} \text { and } i \in I\right.
$$

We assume products will be launched at a certain and unknown moment $g \in T H$. Besides, we assume return function of each product is a linear function of the firm's performance advantage corresponding to the product. It means;

$$
d_{i j}=\alpha_{i j}\left(\phi_{i g}-\gamma_{i j}\right) \quad i \in I, j \in T H
$$

where $\alpha_{i j}$ is a fixed positive number as a slope of the linear function. Clearly, in order to make projects available at this moment $(j=0)$, the equation $\phi_{i g}>\gamma_{i 0}$ must hold for all projects. We denote the expected value of $d_{i j}$ by $\overline{d_{i j}}$ and the expected value of $\gamma_{i j}$ by $\overline{\gamma_{i j}}$ as well. Hence;

$$
\begin{aligned}
& \overline{d_{i j}}=\alpha_{i j} \phi_{i g}-\alpha_{i j} \overline{\gamma_{i j}} \\
& \overline{d_{i j}}=\alpha_{i j} \phi_{i g}-\alpha_{i j}\left[p_{i j}\left(\overline{\gamma_{i(j-1)}}+\tau_{i(j-1)}\right)+\left(1-p_{i j}\right)\left(\overline{\gamma_{i(j-1)}}\right)\right] \quad i \in I, j \in T H
\end{aligned}
$$

\footnotetext{
${ }^{1}$ Hence, for simplicity, we occasionally use project and product interchangeably.
} 


$$
\frac{\overline{d_{i j}}}{\overline{d_{i(j-1)}}}=1-\frac{\alpha_{i j} p_{i j} \tau_{i j}}{\overline{d_{i(j-1)}}} \quad i \in I, j \in T H
$$

We define the weakness of competitive market for project $i \in I$ at moment $j \in T H$;

$$
q_{i j}=1-\frac{\alpha_{i j} p_{i j} \tau_{i j}}{d_{i(j-1)}} \quad i \in I, j \in T H
$$

which implies $\overline{d_{i j}}=q_{i j} \overline{d_{i(j-1)}}$ and determines how the return is adjusting during time horizon.

For simplicity, from now we assume the weakness of competitive market as the given information.

\subsection{Project implementation}

We assumed that project $i \in I$ can start at any moment, then for $\omega_{i}$ following moments, this project requires investment equals to $c_{i j}^{t}$ for $t$ th moment of the project. In other words, the project is not interrupted until its completion. Once the investment is completed, project will start generating return until the end of the time horizon. According to the computation in section 3.1, the system equations of return is hold as follows;

$$
\begin{aligned}
& \overline{d_{i 0}}=\pi_{i}, \quad i \in I \\
& \overline{d_{i j}}=q_{i j} \overline{d_{i(j-1)}}, \quad j=1, \ldots, s_{i}-1, \quad i \in I \\
& \overline{d_{i j}}=0, \quad j=T H-\left\{0,1, \ldots, s_{i}-1\right\}, \quad i \in I
\end{aligned}
$$

where $\pi_{i}$ is the initial return of product $i \in I$ and $s_{i}$ is the last allowed moment of achieving return by product $i \in I$ and is defined by;

$$
s_{i}=\left\{j \in T H \mid \frac{\overline{d_{i(j-1)}}}{\overline{d_{i 0}}}>\varepsilon, \frac{\overline{d_{i j}}}{\overline{d_{i 0}}} \leq \varepsilon\right\} \quad \text { for } i \in I
$$

So $\varepsilon$ will be the control parameter for the ratio of the last return to the initial moment return.

Decisions will be made in a finite time horizon, so the final moment of modelling $(T)$ should be determined. Definition of $s_{i}$ allows decision makers to consider a reasonable time horizon;

$$
T \geq \max _{i}\left\{s_{i}\right\} .
$$

The above constraint forces time horizon at a moment that all products have the chance to gain the returns, completely.

On the other hand, potentially, managers must be able to perform every project under given time horizon;

$$
T \geq \max _{i}\left\{\omega_{i}\right\}
$$

Eq. (9) and Eq. (10) permit managers to apply reasonable amount of $T$ as a given information.

\subsection{Interactions between projects}

Another important part of our modelling is about the benefit interactions among projects. Benefit interactions may occur if the impacts of projects are non-additive. Typically, in this case, products may substitute or complement one another (Eilat et al., 2006; Loch \& Kavadias, 2008). So two subset of projects are defined as follow: $C P$ is a set of ordered pairs $\left(i, i^{\prime}\right)$ where $i, i^{\prime} \in I$ and launching project $i$ forces launching project $i$ and vice versa (launching project $i$ forces launching project $i$ ). It is interesting to note that if $\left(i, i^{\prime}\right) \in C P$, then $\left(i^{\prime}, i\right) \in C P$. On the other hand, $S P$ is a set of ordered pairs 
$\left(i, i^{\prime \prime}\right)$ where $i, i^{\prime} \in I$ and launching project $i$ prevents launching project $i^{\prime \prime}$ and vice versa (launching project $i "$ prevents launching project $i$ ).

The new developed products may exhibit synergies in a portfolio. $A P=\left\{A P_{1}, A P_{2}, \ldots, A P_{r}\right\}$ is a set of potential outcome interactions among various combinations of projects and $A P I=\{1,2, \ldots, \mathrm{r})$ is a set of indices corresponding to $A P$ so that each $A P_{h} \quad h \in A P I$ includes several (more than one) projects that launching all of them produces more return than individually launching. If this interaction occurs at moment $t, r d_{h t}$ units of return would be added to the total return.

The last type of interactions in this paper is resource interactions. Resource interactions may occur if the total resource requirement of projects in the portfolio is less than the sum of the resources of the individual projects. Similar to outcome interactions, $R P=\left\{R P_{1}, R P_{2}, \ldots, R P_{r}\right\}$ is a set of potential resource interactions between various combinations of projects and $R P I=\{1,2, \ldots, \mathrm{f})$ is a set of indices corresponding to $R P$. Thus, each $R P_{k} \quad \mathrm{k} \in R P I$ includes several (more than one) projects that performing all of them together saves resources more than individually performing. If this interaction occurs at any moment, $r c_{k}$ units of return would be added to the total return.

\subsection{Liabilities}

The main sources for financing the projects are liabilities. The financial institutions look for the credit of the firm to lend loans. We represent this credibility by guarantee parameter $\kappa$ which is a low amount for small and medium businesses and as the firm expands, it increases to infinite amount (Kang, 2005; Xiang \& Yang, 2015). In this model, we denote set of available loans by $L=\{1, \ldots, n\}$, so there are $n$ available loans which can be adopted at any moments within time horizon. One moment after receiving loan $u_{l}$, associated repayments $b_{l}$ will begin for $\theta_{l}$ consecutive time instants.

\subsection{Proposed model}

First of all, the variables in the proposing model are as follow:

$x_{i j}$ Binary variable equals to 1 if project $i \in I$ starts at moment $\mathrm{j}$, and equals to 0 otherwise

$y_{i j}$ Binary variable equals to 1 if project $i \in I$ be invested at moment $\mathrm{j}$, and equals to 0 otherwise

$z_{i j}$ Binary variable equals to 1 if project $i \in I$ gained at moment $j \in T H$, and equals to 0 otherwise

$a_{l j}$ Binary variable equals to 1 if loan $l \in L$ be received at moment $j \in T H$, and equals to 0 otherwise

$v_{k j}$ Binary variable equals to 1 if resource interaction $k \in R P I$ be true at moment $j \in T H$, and equals to 0 otherwise

$w_{h j}$ Binary variable equals to 1 if synergy interaction $h \in A P I$ be true at moment $j \in T H$, and equals to 0 otherwise

$P_{j}$ Firm's property at moment $j \in T H$

$S_{j}$ Surplus of investment in period $j \in T H$

$f$ Profit that is gained by the firm as the objective function

The aim of this model is to maximize the profit that is made by project returns and loans, and also minimizing the cost that occurs by project investments and repayments over the time horizon. The objective function is formulated as follows; 


$$
f=v+\sum_{t=0}^{T}\left(\sum_{i=1}^{m} \sum_{j=0}^{t-\omega^{i}} \overline{d_{i t}} x_{i j}+\sum_{h=1}^{r} r d_{h t} w_{h t}+\sum_{l=1}^{n} u_{l} a_{l t}-\sum_{i=1}^{m} \sum_{j=0}^{t} c_{i t}^{t-j} x_{i j}+\sum_{k=1}^{f} r c_{k} v_{k t}-\sum_{l=1}^{n} \sum_{j=0}^{t} b_{l t}^{t-j} a_{l j}\right)
$$

where $\sum_{i=1}^{m} \sum_{j=0}^{t} c_{i t}^{t-j} x_{i j}$ is total cost on the pool of selected projects at moment $t, \sum_{i=1}^{m} \sum_{j=0}^{t-\omega_{i}} \bar{d}_{i t} x_{i j}$ is the total return of the portfolio at moment $t, \sum_{l=1}^{n} u_{l} a_{l t}$ is the total loans received from the banks at moment $t$ and $\sum_{l=1}^{n} \sum_{j=0}^{t} b_{l t}^{t-j} a_{l j}$ is the total repayments of received loans at moment $t$. Also, $\sum_{h=1}^{r} r d_{h t} w_{h t}$ is the total benefit that is gained due to synergies between products at moment $t$, and $\sum_{k=1}^{f} r c_{k} v_{k t}$ is the total resource-saving caused by resource interactions between projects at moment $t$.

Evidently, at each moment, the invested money is less than the revenue of the firm. Therefore, the money, which is gained and not invested is transferred to the next moment. So the following constraint should be hold at every moment.

$$
\begin{aligned}
& \sum_{i=1}^{m} \sum_{j=0}^{t} c_{i t}^{t-j} x_{i j}-\sum_{k=1}^{f} r c_{k} v_{k t}+\sum_{l=1}^{n} \sum_{j=0}^{t} b_{l t}^{t-j} a_{l j}+S_{t}=P_{t}+\sum_{i=1}^{m} \sum_{j=0}^{t-\omega^{i}} \overline{d_{i t}} x_{i j}+\sum_{h=1}^{r} r d_{h t} w_{h t}+\sum_{l=1}^{n} u_{l} a_{l t}, \\
& t=0, \ldots, \mathrm{T}
\end{aligned}
$$

Consequently, the integration between consecutive moments is satisfied by the following constraints;

$$
\begin{aligned}
& P_{0}=v \\
& P_{j}=S_{j-1}, \quad j=1, \ldots, \mathrm{T}
\end{aligned}
$$

where $v$ is the firm's initial investment.

Assertion 1: The objective of the model must be defined as maximization in surplus of the revenues at final decision-making moment;

$$
\max f=S_{T}
$$

Proof 1:

Based on Eq. (11) and Eq. (12), we rewrite the objective function as below;

$$
f=v+\sum_{j=0}^{T}\left(S_{j}-P_{j}\right), \text { or } f=v-P_{0}+S_{0}-P_{1}+S_{1}+\ldots-P_{T}+S_{T} \text { Thus } f=v-P_{0}+\sum_{j=1}^{T}\left(S_{j-1}-P_{j}\right)+S_{T}
$$

Since constraints (13) and (14) hold, so;

$f=S_{T}$

As we expressed, the important point about loans are the ability of the firm to repay the loans;

$$
\sum_{l=1}^{n} \sum_{j=\max \left(0, t-\theta^{l}\right)}^{t} u_{l} a_{l j} \leq \kappa, \quad t=0, \ldots, \mathrm{T}
$$

where $\kappa$ represents the ability of the firm in receiving loans and we call it guarantee. Constraint (16) imposes that the bank would not give loans more than the credit of the firm and limits the liabilities.

Determined time horizon does not permit managers to adopt the loans at any time. Absolutely, the last moments of decision-making are not appropriate times for receiving loans, because corresponding repayment durations exceed time horizon. Following constraint ensure us about the related issue; 
$\sum_{l=1}^{n} \sum_{j=T-\theta^{l}+1}^{54} a_{l j}=0$

As mentioned before, products may substitute or complement one another. Conditions for complementary pair of products that both products must be launched to the market at the same moment, are as follows;

$$
\begin{aligned}
& x_{i j} \leq x_{i^{\prime}\left(j+\omega_{i}-\omega_{i^{\prime}}\right)},\left(i, i^{\prime}\right) \in C P, j=\max \left\{\omega_{i^{\prime}}-\omega_{i}, 0\right\}, \ldots, \mathrm{T}-\max \left\{\omega_{i^{\prime}}, \omega_{i}\right\} \\
& x_{i j}=0, \quad\left(i, i^{\prime}\right) \in C P, j=0, \ldots, \omega_{i^{\prime}}-\omega_{i}-1, \text { if } \omega_{i^{\prime}}>\omega_{i}
\end{aligned}
$$

On the other hand, the constraint to substitute products are described as follows;

$$
\sum_{j=0}^{T} x_{i j} \leq 1-\sum_{j=0}^{T} x_{i^{\prime \prime} j}, \quad\left(i, i^{\prime \prime}\right) \in S P
$$

It is important to state how the model determines the moments which interactions between projects lessen using resources. The following constraints reveal these moments;

$$
\begin{aligned}
& x_{i j} \leq y_{i(j+t)}, \quad j=0, \ldots, \mathrm{T}, \quad i \in R P_{k} t=0, \ldots, \min \left(\mathrm{T}-\mathrm{j}, \omega_{i}-1\right), \\
& k \in R P I \\
& \sum_{i=0}^{j} x_{i t} \geq y_{i j}, \quad j=0, \ldots, \mathrm{T}, \quad k \in R P I, \quad i \in R P_{k} \\
& \sum_{j=0}^{T} y_{i j} \leq \omega_{i}, \quad k \in R P I, \quad i \in R P_{k} \\
& v_{k j} \leq y_{i j}, \quad k \in R P I, \quad i \in R P_{k}, \quad j=0, \ldots, \mathrm{T} \\
& v_{k j} \geq \sum_{i \in R P_{k}} y_{i j}-\left|R P_{k}\right|+1 . \quad k \in R P I, \quad j=0, \ldots, \mathrm{T}
\end{aligned}
$$

Synergy among different projects brings more profit to the objective function at particular time instants that are imposed at the following constraint;

$$
\begin{aligned}
& x_{i j} \leq z_{i\left(j+\omega_{i}\right)}, \quad j=0, \ldots, \mathrm{T}-\omega_{i}, \quad h \in A P I, \quad i \in A P_{h} \\
& z_{i j} \leq z_{i(j+1)}, \quad j=0, \ldots, \mathrm{T}-1, \quad h \in A P I, \quad i \in A P_{h} \\
& \sum_{k=0}^{j} x_{i k} \geq z_{i\left(j+\omega^{i}\right)}, \quad j=0, \ldots, \mathrm{T}-\omega_{i}, \quad h \in A P I, \quad i \in A P_{h} \\
& 1-x_{i j} \geq z_{i\left(j+\omega_{i}-1\right)}, \quad j=0, \ldots, \mathrm{T}-\omega_{i}+1, \quad h \in A P I, \quad i \in A P_{h} \\
& w_{h j} \leq z_{i j}, \quad h \in A P I, \quad i \in A P_{h}, \quad j=0, \ldots, \mathrm{T} \\
& w_{h j} \geq \sum_{i \in A P_{h}} z_{i j}-\left|A P_{h}\right|+1, \quad h \in A P I, \quad j=0, \ldots, \mathrm{T}
\end{aligned}
$$

Absolutely, each project can be chosen at most once;

$$
\sum_{j=0}^{T} x_{i j}<=1, \quad i \in I
$$

Similarly, the same condition should be presented for loans;

$$
\sum_{j=0}^{T} a_{i j}<=1, \quad l \in L
$$

According to definition of variables, all of them have special restrictions;

$$
P_{j}>=0, \quad j=0, \ldots, T
$$


$S_{j}>=0, \quad j=0, \ldots, T$

$x_{i j} \in\{0,1\}, \quad j=0, \ldots, T, \quad i \in I$

$y_{i j} \in\{0,1\}, \quad j=0, \ldots, T, \quad i \in I$

$z_{i j} \in\{0,1\}, \quad j=0, \ldots, T, \quad i \in I$

$v_{k j} \in\{0,1\}, \quad j=0, \ldots, T, \quad k \in R P I$

$w_{h j} \in\{0,1\}, \quad j=0, \ldots, T, \quad h \in A P I$

$a_{i j} \in\{0,1\}, \quad j=0, \ldots, T, \quad l \in L$

Regarding the system of constraints (12)-(41) at each time instants, it is possible to choose some projects. In contrast, if there is no property, loan and return, none of the projects is performed. Therefore, there is always at least one feasible solution for the suggested mathematical model.

This model is coded in Python programming environment by applying pulp (Mitchell et al., 2011) module. Furthermore, some packages and modules such as numpy, openpyxl, math and matplotlib were helpful, too.

\section{Model Analysis}

In this section, a numerical example is presented to demonstrate the applicability of the proposed approach. The initial data are captured from a reputable telecommunication company which deals with new product development decisions. Generally, many development projects are discovered by company's R\&D team. But nowadays 11 projects are potentially available for putting in the collection of projects and there is only 100 units of initial investment to perform them. These projects are evaluated by their costs and returns and also specific relations among them. 13 experts from different functional departments of the firm determine the data and analyze the result of the model, interactively. Table 2 shows the parameters values (except projects costs) for each project separately.

Table 2

Projects Data

\begin{tabular}{lccc}
\hline & $\omega_{i}$ & $\overline{d_{i 0}}$ & $q_{i j}$ at each $j \in T H$ \\
\hline Project 1 & 4 & 260 & 0.82 \\
Project 2 & 8 & 290 & 0.88 \\
Project 3 & 7 & 220 & 0.87 \\
Project 4 & 3 & 210 & 0.77 \\
Project 5 & 5 & 170 & 0.89 \\
Project 6 & 3 & 150 & 0.81 \\
Project 7 & 7 & 110 & 0.85 \\
Project 8 & 3 & 100 & 0.76 \\
Project 9 & 4 & 280 & 0.8 \\
Project 10 & 4 & 360 & 0.84 \\
Project 11 & 3 & 240 & 0.82 \\
\hline
\end{tabular}

According to Table 2, initial return and weakness for each project is expressed. The latest return was determined by using $\varepsilon=0.05$ and it was fixed to $T=25$. Moreover, how the cash flow during performing projects changes is introduced in Table 3.

Table 3

The cost of different projects 


\begin{tabular}{lccccccccc}
\hline & $c_{i j}^{0}$ & $c_{i j}^{1}$ & $c_{i j}^{2}$ & $c_{i j}^{3}$ & $c_{i j}^{4}$ & $c_{i j}^{5}$ & $c_{i j}^{6}$ & $c_{i j}^{7}$ & $c_{i j}^{t}$ for $t \geq \omega_{i}$ \\
\hline Project 1 & 38 & 66 & 68 & 32 & 0 & 0 & 0 & 0 & 0 \\
Project 2 & 21 & 34 & 39 & 46 & 42 & 33 & 24 & 17 & 0 \\
Project 3 & 19 & 25 & 28 & 33 & 30 & 22 & 18 & 0 & 0 \\
Project 4 & 44 & 56 & 47 & 0 & 0 & 0 & 0 & 0 & 0 \\
Project 5 & 21 & 25 & 31 & 27 & 26 & 0 & 0 & 0 & 0 \\
Project 6 & 34 & 37 & 31 & 0 & 0 & 0 & 0 & 0 & 0 \\
Project 7 & 9 & 12 & 15 & 18 & 14 & 13 & 10 & 0 & 0 \\
Project 8 & 17 & 24 & 16 & 0 & 0 & 0 & 0 & 0 & 0 \\
Project 9 & 40 & 44 & 43 & 33 & 0 & 0 & 0 & 0 & 0 \\
\hline Project 10 & 51 & 84 & 79 & 54 & 0 & 0 & 0 & 0 & 0 \\
Project 11 & 36 & 48 & 45 & 0 & 0 & 0 & 0 & 0 & 0 \\
\hline
\end{tabular}

Several banks represent some loans to facilitate the firm's strategy. The banks demand guarantee for granting loans. Maximum available guarantee is about 100. Existing loans with their specifications are shown in Table 4.

Table 4

The information of loans

\begin{tabular}{lccc}
\hline & $b_{l j}^{t}$ at $1 \leq t \leq \theta_{l}$ for each $j \in T H$ & $u_{l}$ & $\theta_{l}$ \\
\hline Loan A & 22 & 62 & 3 \\
Loan B & 12 & 54 & 5 \\
Loan C & 6 & 35 & 6 \\
\hline Loan D & 10 & 45 & 5 \\
\hline
\end{tabular}

Surely, $b_{l j}^{t}$ for other amounts of $t$ equals to zero. Four types of interactions are as follows;

$R P=\{\{5,6,7\},\{2,3\}\}$ that means for instance if projects 5, 6 and 7 have mutual moments in their performing, managers are able to save a specific amount of money. In this example, $r c_{1}=16$ and $r c_{2}=12 . A P=\{\{5,6\},\{10,11\}\}$ that is explained if for example projects 10 and 11 are launched already, at the mutual moments of their launching time, firm can put certain extra revenue to its pocket. Table 5 show how these revenue change over time for described $A P$ set;

Table 5

The information of outcome revenue

\begin{tabular}{llllllllllllllllllllllllllllll}
\hline$t \rightarrow 0$ & 1 & 2 & 3 & 4 & 5 & 6 & 7 & 8 & 9 & 10 & 11 & 12 & 13 & 14 & 15 & 16 & 17 & 18 & 19 & 20 & 21 & 22 & 23 & 24 & 25 & 26 \\
\hline
\end{tabular}





$C P=\{(1,2),(2,1)\}$ implies projects 1 and 2 must be introduced to the market at the same time and $S P=\{(3,4),(4,3)\}$ indicates products 3 and 4 would substitute each other and only one of them can be selected. After running the model with the given information, project 11 is assigned to moment 0 , project 5 to moment 1 , project 6 to moment 3 , etc. Also, loan $\mathrm{A}$ is received at moment 1 , loan $\mathrm{C}$ at moment 2 and loan D at moment 5. Moreover, about 2229 units of profit is gained as objective function. Fig 1 shows the time schedule of running projects, receiving and repaying loans, portfolio making and influence of re-investment strategy. 


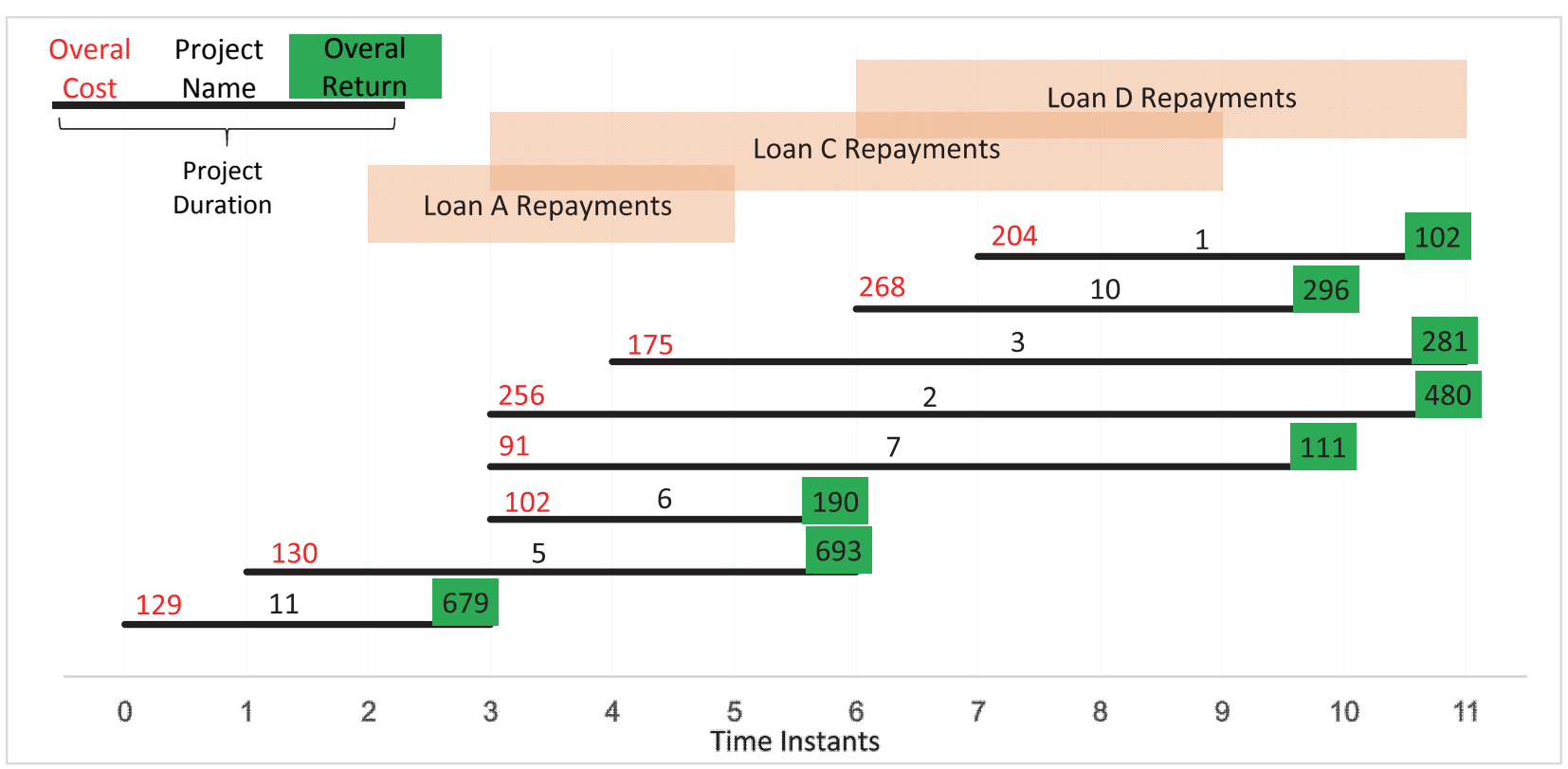

Fig. 1. Portfolio scheduling

Despite performing project 1 forces managers to lose money (Fig. 1), but it is reasonable to run that in an integrated portfolio. According to $C P$ set, project 1 is complement with project 2 . Therefore, interactions among projects are getting more and more level of importance. For the outcome and resource interactions, the relevant variables values are: $v_{0 t}$ at $3 \leq t \leq 5$ equals to 1 and $v_{1 t}$ for $4 \leq t \leq 9$ equals to 1 , too. Also, $w_{0 t}$ at $6 \leq t \leq 25$ equals to 1 and $w_{1 t}$ for $10 \leq t \leq 25$ equals to 1 , too. At other time instants which are not mentioned, $v_{k t}$ and $w_{h t}$ are equal to zero.

\subsection{Sensitivity to the competitive environment}

In order to capture competitive environment, we supposed return is varying based on Eq. (6). By changing the weakness of competitive environment for all products to less than their actual amounts, the objective function changes as Fig. 2 (for calculating objective function, we ignored initial investment).



Fig. 2. Profit on stronger market 
Obviously, total profit is declining quickly since weakness of competitive environment reduces (strength of competitive environment grows). This trend continues to about $74 \%$ of present weakness, then it falls down to zero. In other words, only $35 \%$ progress in strength of competitiveness is required to make the whole of the portfolio valueless. Such a sensitivity to market highlights the importance of paying attentions to environment around the firm. If the weakness of competitive environment $\left(q_{i j}\right)$ equals to 1 for every project at each moments, parameter $d_{i j}$ remains fix during time. Holding such a condition will make the model unrealistic. For example, neglecting constraint (9) and considering $T=12$. See how the objective function increases from 1394 (with real $q_{i j}$ ) to 11695 (with $q_{i j}=1$ ). Absolutely, if we suppose $T$ larger, the state becomes worse. This deceptive profit as a wrong estimation will put the firm into trouble in future. Other ways to express return include earning at once (GZ, 1991) or earning at a finite duration (Jafarzadeh et al., 2015). Since, return is receiving during the time, these ways are not able to illustrate problem space correctly.

\subsection{Flexibility of time horizon}

As before, constraint (9) is out of the model. Measuring profit by holding different quantity of $T$ and number of selected projects are represented in Fig. 3. Fig. 3 demonstrates how considering longer time horizon give chances to more projects to be chosen. Also, as the time horizon extends, objective function value changes to larger profit. This result may induce decision-makers to adopt wide time horizon, but future parameter values are less reliable than close ones, because as we step forward at time, the accuracy of data reduces. Therefore, decision-makers should do a trade-off between uncertainty in the future parameters and unprofitability of short time horizon.

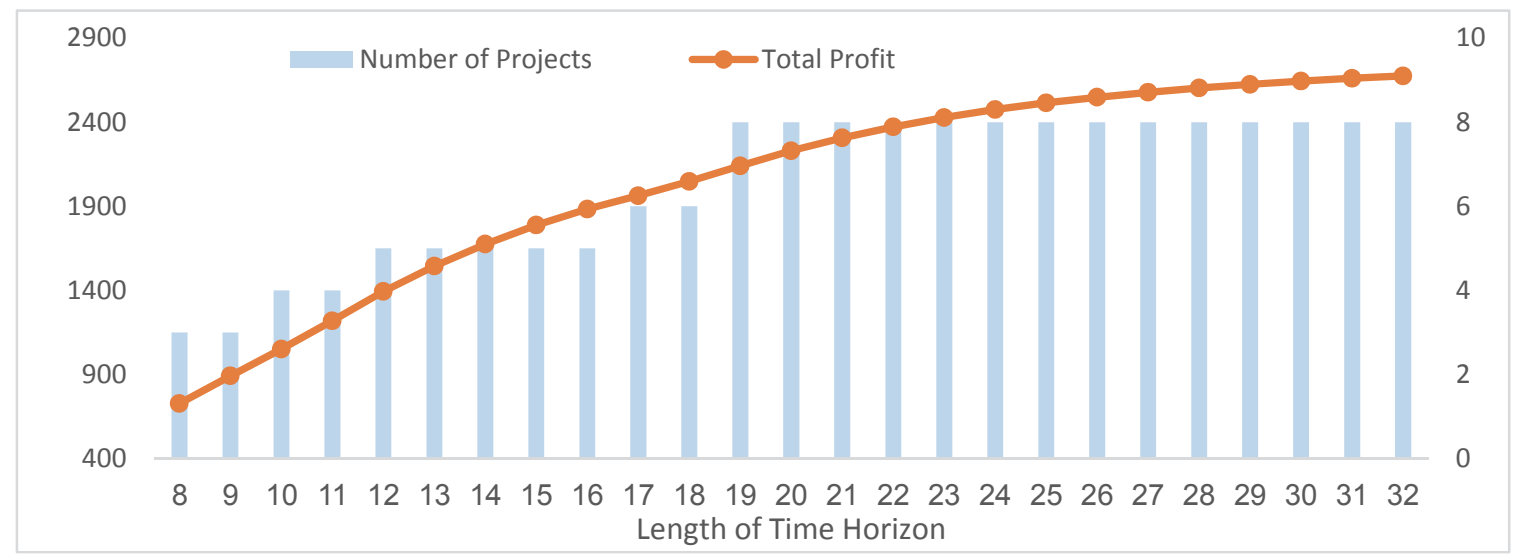

Fig. 3. Profit and number of projects on different time horizon

\subsection{Capability of the firm}

Excepted return of the products and financing the projects will be accomplished through bank loans or investment. Each of these ways confronts with some restrictions. First, no bank grants a loan without any guarantees which shows credibility of the firm. In addition, the firm is capable of financing from the other sources up to a particular volume. Managers may finance from other ways, or have an initial wealth which it tends to be invested in the portfolio. However, obviously as the initial investment of the firm increases, the total profit of the firm rises, too. But in order to see how guarantee restriction can effect on the profit, we bring back constraint (9), fix time horizon at $T=25$ and run the model for different quantities of guarantee and the results shown in Fig. 4 are obtained. As demonstrated in Fig. 4, profit increases monotonically by increasing the limit of liability. This emphasizes on how the credibility of 
the firm facilitates receiving loans and brings more profit. By giving assurance to the banks, managers are able to take strategic decisions more safely.

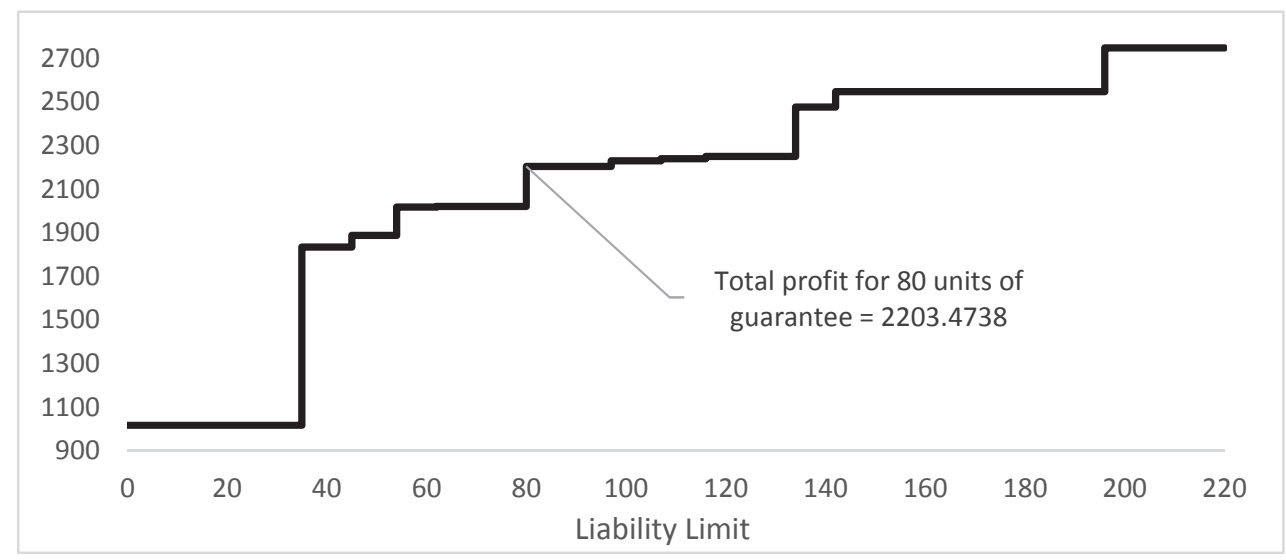

Fig. 4. Profit on different liability limit

\subsection{Absence of interactions}

For further analysis suppose that we use the proposed model without outcome interactions and resource interactions $(R P=\{\}$ and $A P=\{\})$ to determine the objective function. In the presence of both mentioned interactions, as calculated before, the objective is $f=2229$. In the absence of only resource interactions, we obtain $f=2100$ (5.8\% reduction) and in the absence of only outcome interactions, the objective becomes $f=1758$ (21.1\% reduction). Moreover, in the absence of both resource and outcome interactions, $f=1562$ units of profit is obtained (29.9\% reduction).

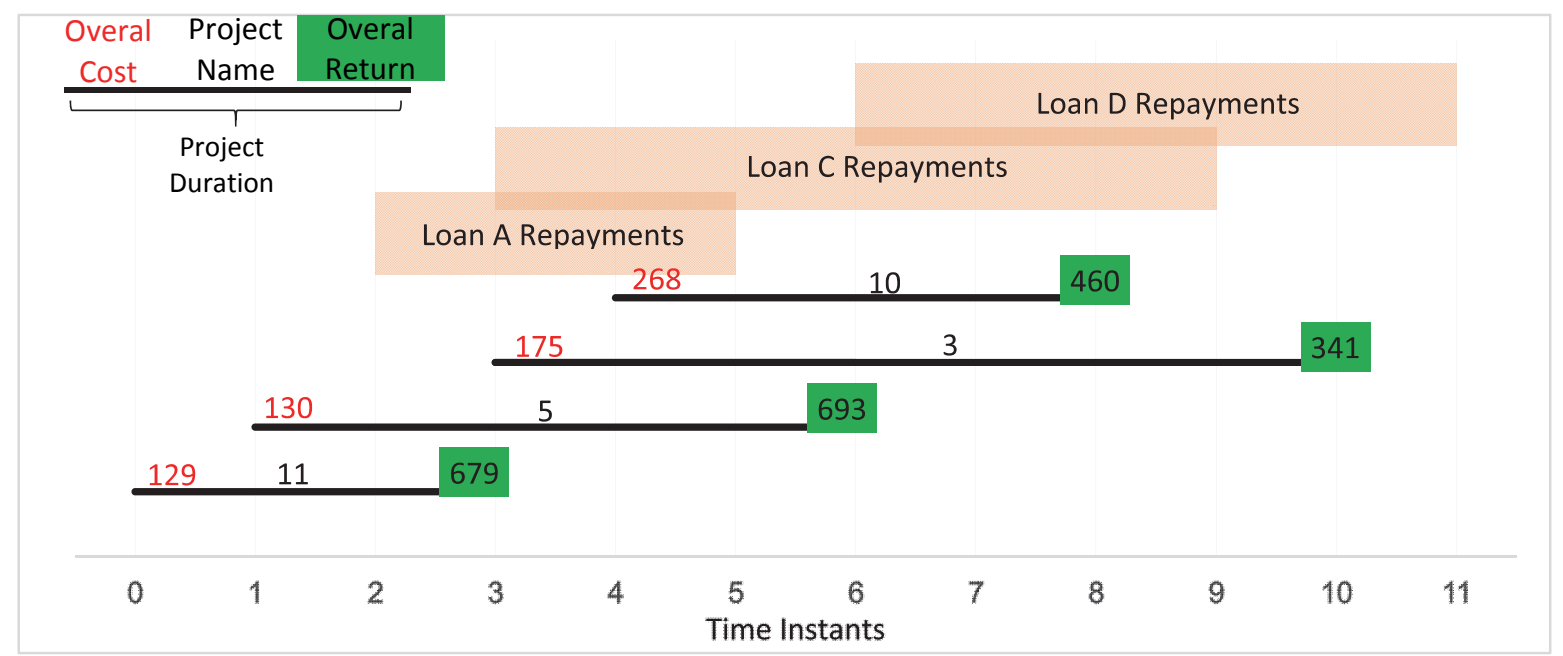

Fig. 5. Portfolio schedule in absence of interactions

Fig. 5 demonstrates how the new model is performed. In comparison with the base model, scheduling of projects changes a lot. Some projects (project1, project2, project7, project6) are removed and total profit is decreased to 0.71 of its real value. This result explains the real definition of portfolio. Profits and also resource consumptions of projects which are members of a portfolio are not additive. Ignoring this assumption may generate unreal solutions. Therefore, we have considered these types of interactions to fill the gap between previous studies. 


\section{Conclusion}

We have developed a new model for NPD portfolio selection with reinvestment strategy within the planning horizon. In this model, we have considered the strength of competitive environment based on two other parameters, then we have modeled the real situations for every final product in the market. For every product, corresponding projects and their cost were considered. Budget constraint does not permit all of the projects to be performed simultaneously. Meanwhile, some interactions among projects restrict the way of their running. In order to confront partially with this issue, we have applied four assumptions. First, there is an initial investment. Second, the firm is able to receive loans under particular condition. Third, we supposed after launching projects, their revenues can be used as costs in performing other projects. Fourth, other types of interactions like outcome and resource interactions turn the model to reality more than before. Numerical analysis have shown how competitive environment has a negative effect on profit and ignoring this condition distance the model from reliable solution. Also, the dilemma between short time horizon and uncertainty in future parameters has been clarified. Further, the credit of the firm as liability limit was measured. Finally, lack of interactions was discussed and emphasized on this prominent part of portfolio theory that has been neglected in most studies. This is the first time that someone noticed the strength of competitive environment in a portfolio of projects. Also, reinvestment strategy for a portfolio of NPD projects has not been studied before. Additionally, applying liability in order to facilitate portfolio selection was suggested for the first time in this paper.

For future research, we propose to investigate on the uncertainty that deals with all parameters. Also, considering ongoing projects and their relations with feasibility of a project may be an interesting topic.

\section{References}

Abbassi, M., Ashrafi, M., \& Sharifi Tashnizi, E. (2014). Selecting balanced portfolios of R\&D projects with interdependencies: A cross-entropy based methodology. Technovation, 34(1), 54-63.

Ahari, S. G., Ghaffari-Nasab, N., Makui, A., \& Ghodsypour, S. H. (2011). A portfolio selection using fuzzy analytic hierarchy process: A case study of Iranian pharmaceutical industry. International Journal of Industrial Engineering Computations, 2(2), 225-236.

Archer, N., \& Ghasemzadeh, F. (1999). An integrated framework for project portfolio selection. International Journal of Project Management, 17(4), 207-216.

Bardhan, I., Bagchi, S., \& Sougstad, R. (2004, January). A real options approach for prioritization of a portfolio of information technology projects: a case study of a utility company. In System Sciences, 2004. Proceedings of the 37th Annual Hawaii International Conference on (pp. 11-pp). IEEE.

Beheshti Pour, B., Noori, S., \& Hosnavi Atashgah, R. (2013). Project selection problem under uncertainty: An application of utility theory and chance constrained programming to a real case. International Journal of Industrial Engineering Computations, 4(3), 373-386.

Belenky, A. S. (2012). A Boolean programming problem of choosing an optimal portfolio of projects and optimal schedules for them by reinvesting within the portfolio the profit from project implementation. Applied Mathematics Letters, 25(10), 1279-1284.

Bhaskaran, S. R., \& Ramachandran, K. (2011). Managing technology selection and development risk in competitive environments. Production and Operations Management, 20(4), 541-555.

Bitman, W., \& Sharif, N. (2008). A conceptual framework for ranking R\&D projects. IEEE Transactions on Engineering Management, 55(2), 267-278.

Boone, J. (2001). Intensity of competition and the incentive to innovate. International Journal of Industrial Organization, 19(5), 705-726.

Brandão, L. E., \& Dyer, J. S. (2011). Valuing real options projects with correlated uncertainties. Journal of Real Options, 1(1), 18-32.

Canbolat, P. G., Golany, B., Mund, I., \& Rothblum, U. G. (2012). A Stochastic Competitive R\&D Race Where "Winner Takes All." Operations Research, 60(3), 700-715.

Carazo, A. F., Gómez, T., Molina, J., Hernández-Díaz, A. G., Guerrero, F. M., \& Caballero, R. (2010). Solving a comprehensive model for multiobjective project portfolio selection. Computers and Operations Research, 37(4), 630-639.

Carlsson, C., Fullér, R., Heikkilä, M., \& Majlender, P. (2007). A fuzzy approach to R\&D project portfolio 
selection. International Journal of Approximate Reasoning, 44(2), 93-105.

Chao, R. O., \& Kavadias, S. (2008). A theoretical framework for managing the new product development portfolio: When and how to use strategic buckets. Management Science, 54(5), 907-921.

Clark, R. E. (1989). Current progress and future directions for research in instructional technology. Educational Technology Research and Development, 37(1), 57-66.

Coffin, M. A., \& Taylor III, B. W. (1996). Multiple criteria R\&amp;D project selection and scheduling using fuzzy logic. Computers \& Operations Research, 23(3), 207-220.

Dutra, C. C., Ribeiro, J. L. D., \& De Carvalho, M. M. (2014). An economic-probabilistic model for project selection and prioritization. International Journal of Project Management, 32(6), 1042-1055.

Eilat, H., Golany, B., \& Shtub, A. (2006). Constructing and evaluating balanced portfolios of R\&D projects with interactions: A DEA based methodology. European Journal of Operational Research, 172(3), 1018-1039.

Etro, F. (2007). Competition, innovation, and antitrust: A theory of market leaders and its policy implications. Berlin ; New York: Springer.

García-Melón, M., Poveda-Bautista, R., \& Del Valle M., J. L. (2015). Using the strategic relative alignment index for the selection of portfolio projects application to a public Venezuelan Power Corporation. International Journal of Production Economics, 170, 54-66.

Gemici-Ozkan, B., Wu, S. D., Linderoth, J. T., \& Moore, J. E. (2010). OR PRACTICE-R\&D Project Portfolio Analysis for the Semiconductor Industry. Operations Research, 58(6), 1548-1563.

Gerchak, Y., \& Parlar, M. (1999). Allocating resources to research and development projects in a competitive environment. Iie Transactions, 31(9), 827-834.

Ghapanchi, A. H., Tavana, M., Khakbaz, M. H., \& Low, G. (2012). A methodology for selecting portfolios of projects with interactions and under uncertainty. International Journal of Project Management, 30(7), 791803.

Ghasemzadeh, F., \& Archer, N. P. (2000). Project portfolio selection through decision support. Decision Support Systems, 29(1), 73-88.

Golany, B., \& Rothblum, U. G. (2008). Optimal investment in development projects. Operations Research Letters, 36(6), 657-661.

Green, J., \& Scotchmer, S. (1995). On the division of profit in sequential innovation. The RAND Journal of Economics, 26(1), 20-33.

GZ. (1991). Optimal sequencing and resource allocation in R\&D projects. Management Science, 37(2), 140-156.

Hassanzadeh, F., Nemati, H., \& Sun, M. (2014). Robust optimization for interactive multiobjective programming with imprecise information applied to R\&D project portfolio selection. European Journal of Operational Research, 238(1), 41-53.

Iamratanakul, S., Patanakul, P., \& Milosevic, D. (2008). Project portfolio selection: From past to present. 2008 4th IEEE International Conference on Management of Innovation and Technology, 287-292.

Imai, J., \& Watanabe, T. (2006). The Investment Game under Uncertainty: An Analysis of Equilibrium Values in the Presence of First or Second Mover Advantage. In Science (p. 151). World Scientific.

Jafarzadeh, M., Tareghian, H. R., Rahbarnia, F., \& Ghanbari, R. (2015). Optimal selection of project portfolios using reinvestment strategy within a flexible time horizon. European Journal of Operational Research, 243(2), 658-664.

Jelassi, M. M. (1999). On closed-form solutions of a resource allocation problem in parallel funding of R \& D projects. Retrieved from http://www.ie.bilkent.edu.tr/ mustafap/pubs/resource_parallel.ps

Kang, D. (2005). Corporate Distress and Restructuring Policy of Korean Small and Medium-sized Enterprises: Role of Credit Guarantee Scheme, (July).

Karaveg, C., Thawesaengskulthai, N., \& Chandrachai, A. (2015). A combined technique using SEM and TOPSIS for the commercialization capability of R\&D project evaluation. Decision Science Letters, 4(3), 379-396.

Kettunen, J., Grushka-Cockayne, Y., Degraeve, Z., \& De Reyck, B. (2015). New product development flexibility in a competitive environment. European Journal of Operational Research, 244(3), 892-904.

Khalili-Damghani, K., Sadi-Nezhad, S., Lotfi, F. H., \& Tavana, M. (2013). A hybrid fuzzy rule-based multi-criteria framework for sustainable project portfolio selection. Information Sciences, 220, 442-462.

Krishnan, V., \& Ulrich, K. T. (2001). Product development decisions: A review of the literature. Management Science, 47(1), 1-21.

Liesiö, J., Mild, P., \& Salo, A. (2007). Preference programming for robust portfolio modeling and project selection. European Journal of Operational Research, 181(3), 1488-1505.

Liesiö, J., Mild, P., \& Salo, A. (2008). Robust portfolio modeling with incomplete cost information and project interdependencies. European Journal of Operational Research, 190(3), 679-695. 
Liesiö, J., \& Salo, A. (2012). Scenario-based portfolio selection of investment projects with incomplete probability and utility information. European Journal of Operational Research, 217(1), 162-172.

Lin, P., \& Zhou, W. (2013). The effects of competition on the R\&D portfolios of multiproduct firms. International Journal of Industrial Organization, 31(1), 83-91.

Loch, C. H., \& Kavadias, S. (2008). Managing new product development: An evolutionary. Handbook of New Product Development Management.

Lunn, J., \& Martin, S. (1986). Market structure, firm structure, and research and development. Quarterly Review of Economics and Business, 26(1), 31-44.

Mavrotas, G., \& Pechak, O. (2013). The trichotomic approach for dealing with uncertainty in project portfolio selection: Combining MCDA, mathematical programming and Monte Carlo simulation. International Journal of Multicriteria Decision Making, 3(1), 79-96.

Medaglia, A. L., Graves, S. B., \& Ringuest, J. L. (2007). A multiobjective evolutionary approach for linearly constrained project selection under uncertainty. European Journal of Operational Research, 179(3), 869-894.

Mehrez, A., \& Sinuany-Stern, Z. (1983). Resource allocation to interrelated risky projects using a multiattribute utility function. Management Science, 29(4), 430-439.

Meskendahl, S. (2010). The influence of business strategy on project portfolio management and its success - A conceptual framework. International Journal of Project Management, 28(8), 807-817. http://doi.org/10.1016/j.ijproman.2010.06.007

Mitchell, S., Mitchell, S., Consulting, S. M., \& Dunning, I. (2011). PuLP: A Linear Programming Toolkit for Python. Retrieved from http://citeseerx.ist.psu.edu/viewdoc/summary?doi=10.1.1.416.4985

Mohanty, R. P., Agarwal, R., Choudhury, a. K., \& Tiwari, M. K. (2005). A fuzzy ANP-based approach to R\&D project selection: A case study. International Journal of Production Research, 43(24), 5199-5216.

Pendharkar, P. C. (2014). A decision-making framework for justifying a portfolio of IT projects. International Journal of Project Management, 32(4), 625-639.

Rajabi Asadabadi, M. (2014). A hybrid QFD-based approach in addressing supplier selection problem in product improvement process. International Journal of Industrial Engineering Computations, 5(4), 543-560.

Salo, A., Keisler, J., \& Morton, A. (2011). An Invitation to Portfolio Decision Analysis (pp. 3-27). http://doi.org/10.1007/978-1-4419-9943-6_1

Shakhsi-Niaei, M., Torabi, S. A., \& Iranmanesh, S. H. (2011). A comprehensive framework for project selection problem under uncertainty and real-world constraints. Computers and Industrial Engineering, 61(1), 226-237.

Shenhar, A. J., Dvir, D., Levy, O., \& Maltz, A. C. (2001). Project success: A multidimensional strategic concept. Long Range Planning, 34(6), 699-725.

Solak, S., Clarke, J. P. B., Johnson, E. L., \& Barnes, E. R. (2010). Optimization of R\&D project portfolios under endogenous uncertainty. European Journal of Operational Research, 207(1), 420-433.

Souza, G. C. (2004). Product introduction decisions in a duopoly. European Journal of Operational Research, $152(3), 745-757$.

Vilkkumaa, E., Liesiö, J., \& Salo, A. (2014). Optimal strategies for selecting project portfolios using uncertain value estimates. European Journal of Operational Research, 233(3), 772-783.

Wang, B., \& Song, Y. (2016). Reinvestment strategy-based project portfolio selection and scheduling with timedependent budget limit considering time value of capital (pp. 373-381). Springer, Berlin, Heidelberg. http://doi.org/10.1007/978-3-662-49370-0_39

Wang, J., \& Hwang, W. L. (2007). A fuzzy set approach for R\&D portfolio selection using a real options valuation model. Omega, 35(3), 247-257.

Wang, J., \& Yang, C. Y. (2012). Flexibility planning for managing R\&D projects under risk. International Journal of Production Economics, 135(2), 823-831.

Wei, C. C., \& Chang, H. W. (2011). A new approach for selecting portfolio of new product development projects. Expert Systems with Applications, 38(1), 429-434.

Xiang, H., \& Yang, Z. (2015). Investment timing and capital structure with loan guarantees. Finance Research Letters, 13, 179-187.

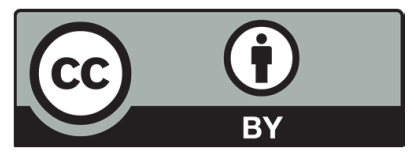

(C) 2017 by the authors; licensee Growing Science, Canada. This is an open access article distributed under the terms and conditions of the Creative Commons Attribution (CCBY) license (http://creativecommons.org/licenses/by/4.0/). 